\title{
Growth and effect of chlamydiae in human and bovine oviduct organ cultures
}

\author{
G. R. HUTCHINSON, D. TAYLOR-ROBINSON, AND R. R. DOURMASHKIN
}

From the Division of Communicable Diseases and Electron Microscopy Section, Clinical Research Centre, Harrow, Middlesex

SUMMARY Organ cultures of 10 Fallopian tubes were inoculated with a genital strain of Chlamydia trachomatis and seven were infected. Infection was enhanced by centrifuging the organisms on to the tissues, larger numbers of organisms being reisolated from the tissues after this procedure. There was evidence of chlamydial multiplication because the number of organisms which were recovered from the tissues three to five days after inoculation had increased. Recovery was rare, however, after the sixth day, thus suggesting a self-limiting infection. Organ cultures of two bovine oviducts were infected with the bovine abortion strain of Chlamydia psittaci, but in these experiments centrifugation of the inocula did not enhance infection. The organisms were found in both the tissue and medium of cultures up to 18 days after inoculation and in much greater numbers than in the $C$. trachomatis-infected Fallopian cultures. Chlamydial infection was not entirely host-tissue specific, because $C$. trachomatis organisms were isolated from bovine oviduct cultures. Inclusions, however, were not detected histologically or electron microscopically in the epithelium of $C$. trachomatis-infected cultures, but they were detected by these means in $C$. psittaci-infected bovine cultures. All the elements of the chlamydial growth cycle were seen by electron microscopy, organisms being found in ciliated and possibly non-ciliated cells, and shedding of some infected epithelial cells was observed. No evidence of extensive epithelial cell damage was observed, however, and no loss of ciliary activity was detected in cultures infected with either $C$. trachomatis or $C$. psittaci when compared with uninoculated cultures. Thus acute salpingitis, when caused by chlamydial infection, is probably immunologically mediated.

\section{Introduction}

Chlamydia trachomatis is a cause of several diseases in human subjects, including trachoma and inclusion conjunctivitis and non-specific urethritis in men. In women, however, the association of chlamydiae with genital disease is less clear. Although chlamydiae can be isolated from women with cervicitis, and may cause the disease in some (Oriel et al., 1974; Rees et $a l .$, 1977), they can also be isolated from apparently healthy women (Oriel et al., 1974). The association between chlamydiae in the cervix and acute pelvic inflammatory disease is more obscure, but the direct isolation of chlamydiae from Fallopian tubes of patients with acute salpingitis (Eilard et al., 1976; Mårdh et al., 1977) suggests that the organisms are

Address for reprints: Dr D. Taylor-Robinson, Division of Communicable Diseases, Clinical Research Centre, Watford Road, Harrow, Middlesex HAI 3UJ

Received for publication 6 October 1978 pathogenic in the upper genital tract. To substantiate this, further isolation and serological studies are required. In addition, however, studies of Fallopian tube organ cultures experimentally infected with chlamydiae might prove valuable. This system has already been useful in studying the pathogenicity of other micro-organisms, including mycoplasmas (Taylor-Robinson and Carney, 1974; Stalheim et al., 1976; Mårdh et al., 1976) and Neisseria gonorrhoeae (McGee et al., 1976), and the mechanisms underlying the gonococcal disease process (Johnson et al., 1977).

We have investigated the effect of $C$. trachomatis on human Fallopian tube organ cultures and of Chlamydia psittaci on bovine oviduct organ cultures.

\section{Materials and methods}

MEDIA

Before inoculation, organ cultures were maintained in Earle's Minimal Essential Medium with 
L-glutamine (Gibco Biocult) containing $50 \mu \mathrm{g} / \mathrm{ml}$ streptomycin, $100 \mu \mathrm{g} / \mathrm{ml}$ vancomycin, 50 units $/ \mathrm{ml}$ nystatin, $0.025 \mathrm{~mol} / 1$ HEPES buffer and $\mathrm{NaHCO}_{3}$ to adjust the $\mathrm{pH}$ to $7 \cdot 4$.

After inoculation of chlamydiae, organ cultures were maintained in the medium described above supplemented with $10 \%$ fetal calf serum and $5 \%$ glucose.

\section{TISSUE AND PREPARATION}

Human Fallopian tube tissue was obtained from premenopausal women undergoing abdominal hysterectomy at Northwick Park Hospital. Bovine oviducts were obtained from animals at slaughter at the Institute for Research on Animal Diseases (Compton) and were placed in maintenance medium for transport to the laboratory. Organ cultures were prepared within one hour of removal of human Fallopian tubes and within two hours of removal of bovine oviducts. The tubes were placed in maintenance medium and the procedures previously described for organ culture preparation (McGee $e t$ al., 1976) were used. Two to three pieces of tissue, each about $0.75 \mathrm{~cm}^{2}$, were placed in $5-\mathrm{cm}$ plastic Petri dishes containing $2 \mathrm{ml}$ of maintenance medium. The cultures were incubated at $37^{\circ} \mathrm{C}$ in an airtight, plastic box gassed with $5 \% \mathrm{CO}_{2}$ in air. Immediately before inoculation the maintenance medium was replaced by growth medium and one hour after inoculation this was removed and replaced by fresh growth medium.

\section{INOCULATION OF ORGAN CULTURES}

The inocula comprised a strain of $C$. trachomatis (78a) isolated from a patient with nongonococcal urethritis, which had been passed twice in irradiated McCoy cells, and the bovine abortion strain of $C$. psittaci passed three times in McCoy cells. Each dish contained $0.2 \mathrm{ml}$ of chlamydial inoculum and $1.8 \mathrm{ml}$ of growth medium, which produced a final concentration of $10^{4}-10^{5}$ inclusion-forming units per $\mathrm{ml}$ of medium. In some experiments, the pieces of tissue were placed mucosal-side uppermost in $1-\mathrm{cm}$ diameter, flat-bottomed tubes, and the inoculum in 2 $\mathrm{ml}$ of medium was centrifuged on to the tissue at $2800 \times g$ for one hour.

Organ cultures used as controls were inoculated with growth medium alone and were treated in all procedures in the same way as infected cultures.

ISOLATION OF CHLAMDIAE

A piece of tissue, about $2 \mathrm{~mm}^{2}$, was cut from a larger piece each day. The tissue was homogenised in a TenBroeck grinder in $0.5 \mathrm{ml}$ of fresh growth medium, agitated with glass beads on a Vortex mixer for $\mathbf{3 0}$ seconds, and then centrifuged at $1000 \mathrm{r} / \mathrm{min}$ for five minutes to remove cell debris. The supernatant fluid was mixed with an equal volume of sucrosephosphate buffer and stored in liquid nitrogen. In addition, $0.5 \mathrm{ml}$ of medium was removed from a dish and similarly stored. In four of 10 experiments using C. trachomatis-infected tubes, tissue samples were homogenised in $0.5 \mathrm{ml}$ of the medium from the same dish and no separate medium sample was taken. The stored samples were later inoculated on to irradiated McCoy cells on coverslips for isolation of chlamydiae (Prentice et al., 1976). After incubation at $36^{\circ} \mathrm{C}$ for 48 hours, the cells were fixed in methanol, stained with Giemsa, mounted, and examined by light and darkground microscopy to detect inclusions. An accurate assessment of the number of inclusions was not possible since the cell monolayers were often partially obscured by cell debris.

\section{ASSESSMENT OF CILIARY ACTIVITY}

The ciliary activity of tissue pieces was evaluated by means of an inverted microscope $(\times 100$ magnification) as described previously (McGee et al., 1976). Dishes inoculated with chlamydiae and uninoculated controls were coded before observation to avoid bias.

\section{HISTOLOGY}

Specimens were fixed in formol saline, processed by routine histological methods, and stained with haematoxylin and eosin, Giemsa, or Macchiavello's stain.

\section{ELECTRON MICROSCOPY}

Specimens were fixed in $3 \%$ glutaraldehyde in 0.1 $\mathrm{mol} / \mathrm{l}$ cacodylate buffer $(\mathrm{pH} 7 \cdot 4)$, rinsed in $0.1 \mathrm{~mol} / 1$ cacodylate buffer with $5 \%$ sucrose, and then postfixed in $1 \% \mathrm{OsO}_{4}$ in $0.1 \mathrm{~mol} / 1$ cacodylate buffer. They were dehydrated in acetone and epoxypropane and then embedded in Spurr resin. Sections were cut and stained with uranyl acetate and lead citrate. Electron microscopy was carried out in a Philips EM 300.

\section{Results}

INFECTION OF ORGAN CULTURES

C. trachomatis in Fallopian tube organ cultures

In 10 experiments with different tubes, no organisms were reisolated from the tissue of cultures two hours and one day after inoculation and none, or very few (less than 10 inclusions/coverslip), from the medium. Organisms were isolated, however, from the tissue and, where tested, occasionally from the medium on the second day and subsequently up to day 11 , when the experiments were terminated. In all, seven tubes were successfully infected, chlamydiae being 
reisolated from the tissues in all these cases and from the medium in one experiment where it was tested separately.

\section{Effect of centrifuging the inoculum}

In four experiments, the result of centrifuging the inoculum on to the tissue was compared with that of not doing so. As shown in Table 1, all tissues were infected following centrifugation and also when centrifugation was not undertaken. After centrifugation, however, the number of organisms in the tissues, as judged by the number of inclusions detected in McCoy cells, was at least fivefold greater than without centrifugation.

Table 1 Effect of centrifugation on infection of Fallopian tube organ cultures by C. trachomatis organisms

\begin{tabular}{llc}
\hline & $\begin{array}{l}\text { Total no. of organisms* } \\
\text { and medium }\end{array}$ & reisolated from tissue \\
\cline { 2 - 3 } Experiment no. & Inoculum centrifuged & $\begin{array}{l}\text { Inoculum not } \\
\text { centrifuged }\end{array}$ \\
\hline 1 & 63 & 3 \\
2 & 224 & 48 \\
3 & 168 & 23 \\
4 & 531 & 111 \\
\hline
\end{tabular}

* As assessed by inclusions in Giemsa-stained $x$-irradiated McCoy cells

\section{Duration of infection}

As shown in Table 2, where the results of experiments with centrifuged inocula are presented, the number of chlamydiae detected in the tissues was usually maximal three to five days after inoculation and then decreased thereafter. Apart from one experiment, organisms were not detected after the sixth day whether or not the inocula had been applied by centrifugation. These results suggested that the chlamydial infection was self-limiting in most cases.

Table 2 C. trachomatis organisms in Fallopian tube organ cultures on different days after inoculation

\begin{tabular}{llllllllll}
\hline & \multicolumn{1}{l}{$\begin{array}{l}\text { No. of chlamydial organisms detected in } \\
\text { tissues on indicated days after centrifugation } \\
\text { of inocula }\end{array}$} \\
\cline { 2 - 9 } Experiment no. & 0 & 1 & 2 & 3 & 4 & 5 & 6 & 7 \\
\hline 1 & & ND & ND & & 45 & 18 & ND & ND \\
2 & ND & & 20 & 180 & 24 & ND & ND \\
3 & ND & & 18 & 57 & 90 & 3 & ND & ND \\
4 & ND & ND & 159 & 228 & 21 & 49 & 5 & $16 *$ \\
5 & ND & ND & 5 & 2 & & 5 & 1 & ND \\
\hline
\end{tabular}

*Chlamydiae detected up to day 11 in this experiment $\mathrm{ND}=$ not detected

\section{C. psittaci in bovine oviduct organ cultures}

In two experiments with different tubes, no organisms were isolated one day after inoculation.
Two to three days later, however, they were recovered in equal numbers from both the tissue and the medium each day up to day 14 or 18 when the experiments were terminated. Maximum numbers of organisms (approximately $2 \times 10^{4}$ inclusions/ coverslip) were detected 10 to 12 days after inoculation. This was about 100 -fold more organisms than detected in $C$. trachomatis-infected cultures. Centrifugation of the inoculum did not seem to enhance the extent or duration of infection by $C$. psittaci.

\section{Specificity of infection}

In one experiment, $C$. trachomatis organisms did not infect a rabbit oviduct. Infection was not limited, however, to human tissue because these organisms infected bovine oviduct organ cultures in two experiments, in one of which inoculation was not assisted by centrifugation. The organisms were detected only in the tissues and not beyond the fifth day.

\section{CILIARY ACTIVITY}

Uninoculated organ cultures of human and bovine oviduct usually retained some ciliary activity for two to three weeks, although ciliary activity of all pieces gradually decreased over this time. Centrifugation seemed to have no effect on ciliary activity.

\section{C. trachomatis in Fallopian tube organ cultures}

Ciliary activity was assessed in six experiments. Activity was reduced by about $50 \%$ in two of three experiments in which there was no evidence of chlamydial infection. In the three experiments in which infection occurred, however, no loss of ciliary activity was detected compared with that of the uninoculated control cultures.

\section{C. psittaci and C. trachomatis in bovine oviduct organ cultures}

In two experiments of 14 and 18 days' duration, despite good evidence of infection by $C$. psittaci, no significant loss of ciliary activity occurred compared with that of uninoculated control cultures. The results of one experiment are presented in Fig. 1; the apparently greater loss of ciliary activity in $C$. psittaci-infected cultures noted early after infection was not statistically significant (day three, $\mathrm{P}>0.05$; Student's $t$ test with 2 d.f.). Furthermore, $C$. trachomatis appeared to have no effect.

\section{HISTOLOGICAL APPEARANCE OF TISSUES}

Chlamydial inclusions in cells were sought on days one, five, seven, and 12 after inoculation of oviduct organ cultures. Inclusions were not seen in sections from cultures inoculated with $C$. trachomatis. In 


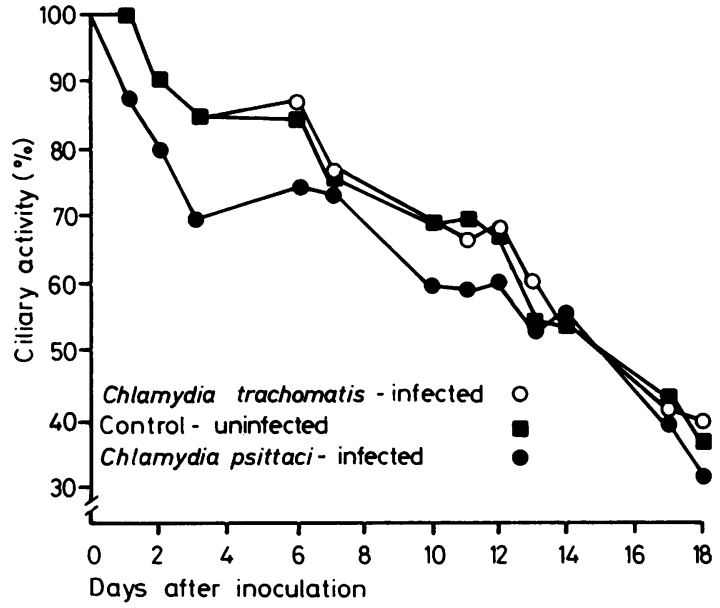

Fig. 1 Ciliary activity of bovine oviduct organ culture after infection by the bovine abortion strain of $\mathrm{C}$. psittaci or C. trachomatis

sections from bovine cultures inoculated with $C$. psittaci, however, inclusions were detected on day five after inoculation and were easily seen on days seven (Fig. 2) and 12. The inclusions were observed in the cytoplasm of cells near the mucosal surface. Although they were seen in cells which did not appear to possess cilia it was not possible to determine whether or not these cells had been ciliated originally. The inclusions were distinct, stained darkblue by Giemsa, and contained particles.

Despite the presence of observable inclusions, at least in the bovine tissues, there was no obvious change in the architecture of the mucosal epithelium of the bovine-infected or human-infected tissues compared with that of the uninoculated controls. Most of the epithelium was ciliated after 12 days in culture, although some sub-epithelial degeneration occurred in both infected and control cultures.

\section{ELECTRON MICROSCOPY}

Chlamydial inclusions in cells could not be detected in sections of Fallopian tube organ cultures inoculated with $C$. trachomatis. Observations, were made on sections of $C$. psittaci-infected bovine oviduct cultures four and seven days after inoculation. Epithelial cells which were seen tended to possess only microvilli-and were, therefore, apparently non-ciliated-and to stain more densely

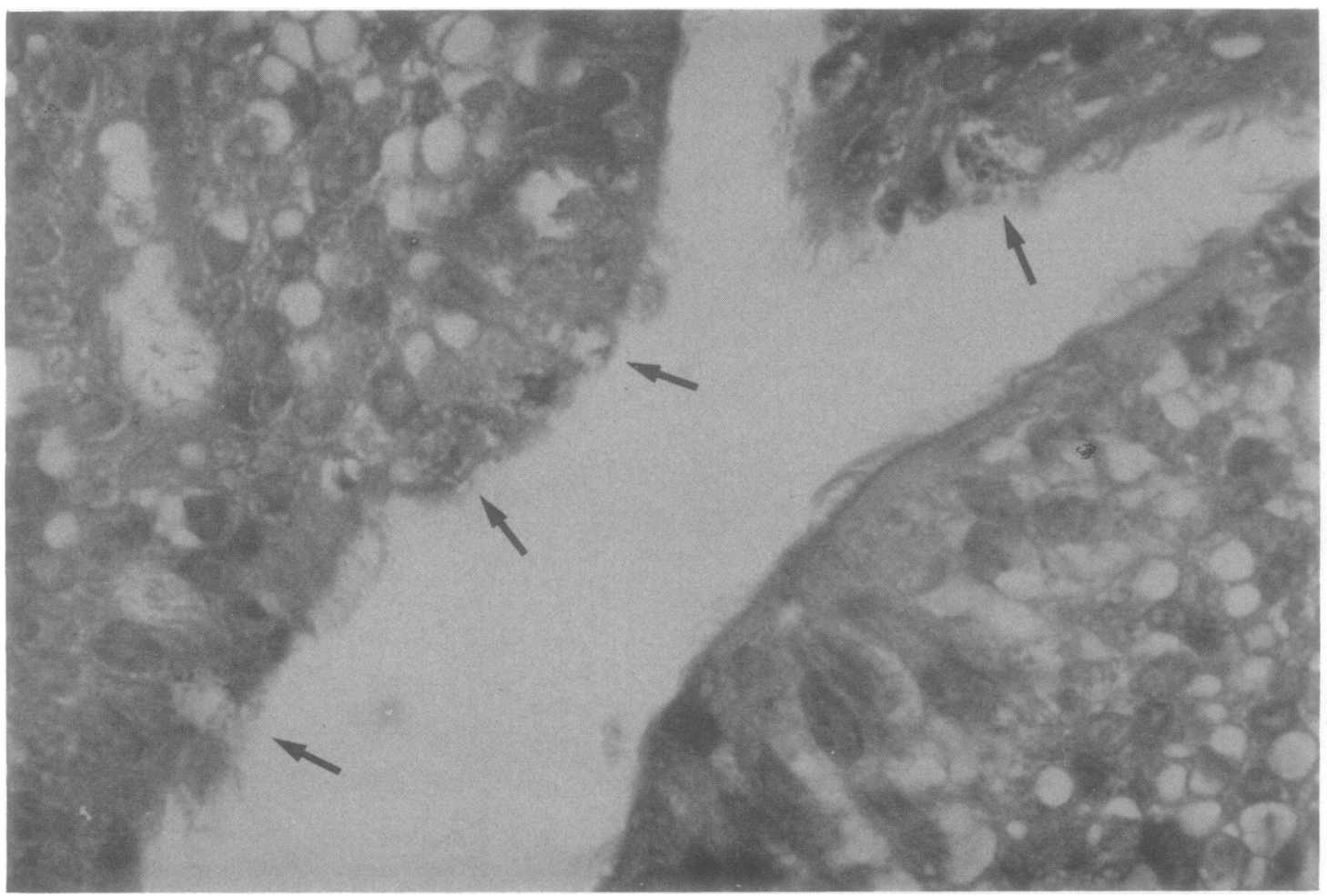

Fig. 2 Histological section of C. psittaci-infected bovine oviduct organ culture. Inclusions (arrowed) in epithelial cells seven days after inoculation. Giemsa $\times 810$ 
than cells which had both microvilli and cilia (Fig. 3). Inclusions were not seen four days after inoculation but they were seen seven days after. They were observed occasionally in epithelial cells which were obviously ciliated (Fig. 4) but more frequently in cells bearing microvilli only. Some of the latter were probably mucus-secreting, non-ciliated cells because they stained densely. It was impossible to know, however, whether or not some of these cells had been ciliated originally but had lost their cilia as a consequence of infection. Some epithelial cells showed evidence of early infection with reticulate bodies only in the cytoplasm (Fig. 5a), while in others infection was more advanced, the inclusions containing reticulate and elementary bodies (Figs. 3, 4 , and $5 b$ ). The cytoplasm and nucleus appeared normal until the late stages of cell infection when the nucleus was sometimes compressed by an inclusion

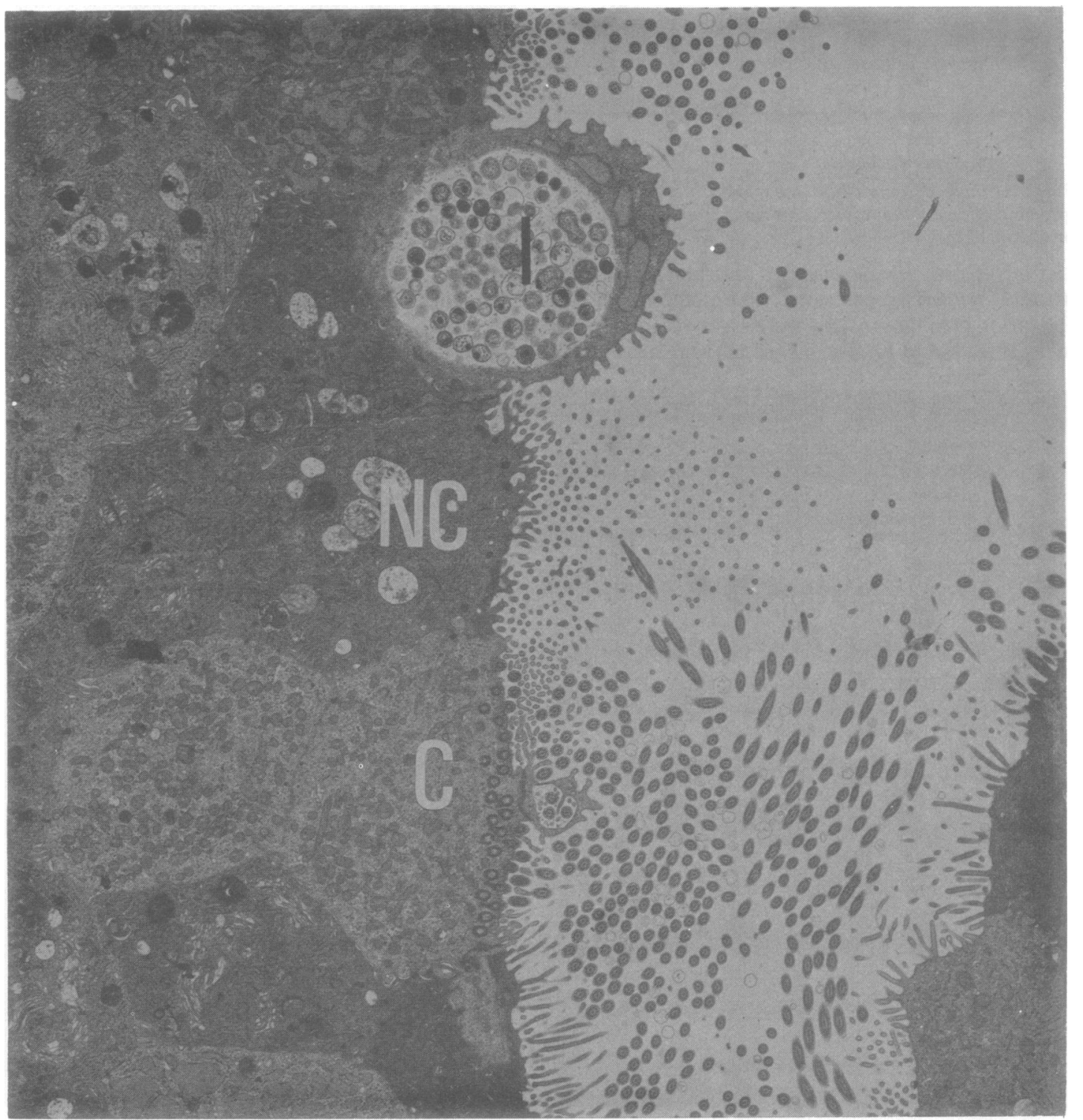

Fig. 3 Electron micrograph of C. psittaci-infected bovine oviduct organ culture seven days after inoculation ( $\times$ 5800). I-inclusion; $C$-ciliated epithelial cell; $N C$-non-ciliated epithelial cell 


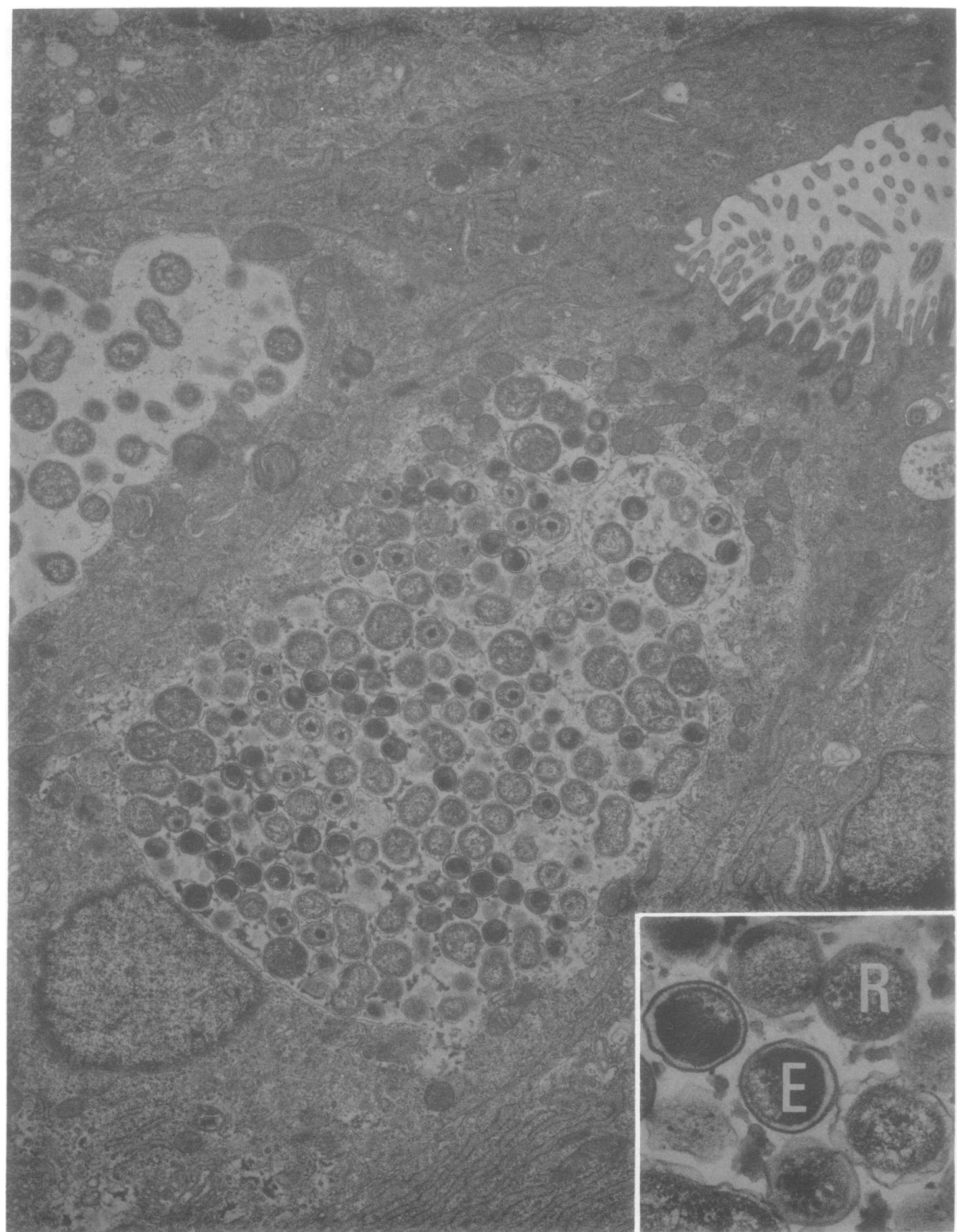

Fig. 4 (and inset) Electron micrograph of C. psittaci-infected bovine oviduct organ culture seven days after inoculation. Inclusion in ciliated epithelial cell (x 11 600). Inset: E-elementary body, $R-$ reticulate body ( $\times 42640)$ 

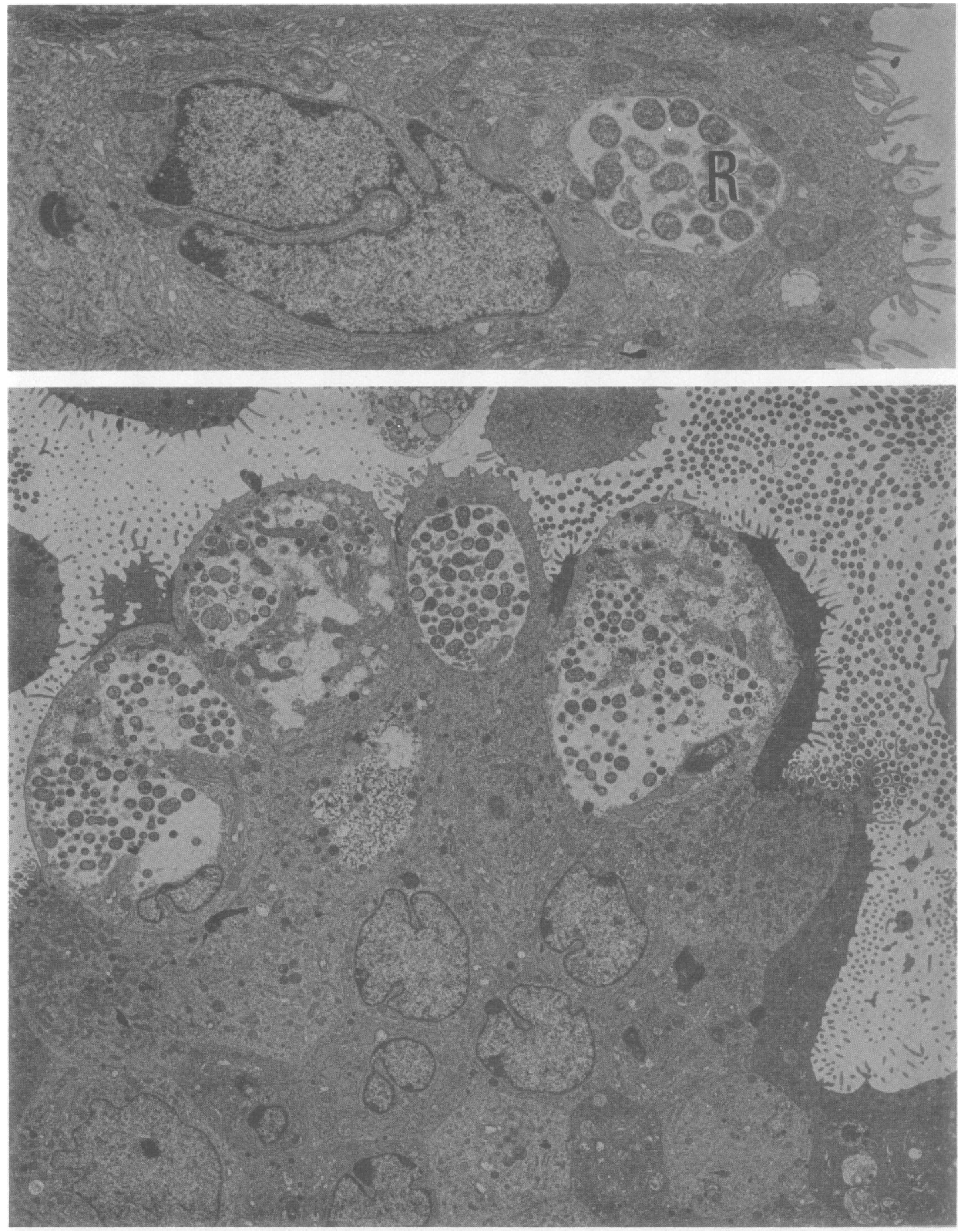

Fig. 5 Electron micrographs of C. psittaci-infected bovine oviduct organ culture seven days after inoculation: (a) Inclusion-containing reticulate bodies $(R)(\times 6400)$; (b) Inclusion-containing cells being extruded from mucosal surface $(\times 3680)$

(a) 
occupying almost the whole of the cytoplasm. At this stage, a cell containing many chlamydial particles was seen occasionally to be in the process of being extruded from the mucosal surface (Figs. 3 and 5 b). Processing the tissues for electron microscopy may have contributed to the failure to see extracellular chlamydial particles.

\section{Discussion}

The results of our attempts to infect human and bovine oviduct mucosae with chlamydiae under experimental conditions show that the oviduct tissues are susceptible to infection. Multiplication of $C$. trachomatis organisms occurred in seven of 10 Fallopian tubes in organ culture. Likewise, replication of organisms of the bovine abortion strain of $C$. psittaci occurred in bovine oviducts, and inclusions produced by these organisms were observed both by light and electron microscopy. Furthermore, replication of the $C$. psittaci strain without centrifugation of the inocula on to the tissues was not difficult to demonstrate, but the small numbers of inclusion-forming units produced by $C$. trachomatis in Fallopian tube cultures were increased by centrifugation of the inocula. The phenomenon of intracellular inclusions increasing in number as a result of inoculum centrifugation has been noted previously for $C$. trachomatis in cell cultures (Darougar et al., 1974) and, of course, can have no parallel in the in-vivo clinical situation, where even small numbers of chlamydial organisms may be able to set up an infection. The apparent self-limiting infection produced by $C$. trachomatis in the organ cultures may be accounted for by the inability of a few liberated chlamydial particles to reinfect without further centrifugation, coupled with epithelial cells which become less susceptible to infection as the organ cultures age. The more prolonged infection by C. psittaci is probably due to liberation of large numbers of organisms into the culture medium and their ability to infect without centrifugation.

The minimal infection of Fallopian tube organ cultures, as indicated by the small number of inclusions which was detected, clearly accounts for the failure to find histological and electron microscopical changes, particularly when only small fragments of tissue were examined. The more extensive infection of bovine oviduct cultures, as indicated by the large number of $C$. psittaci organisms detected in the medium and tissue of the cultures, is in keeping with the ability to observe some histological and electron microscopical changes. These changes, in which all the elements of the chlamydial growth cycle were seen, were similar to those which have been observed in experimentally infected cell cultures (Manire, 1977) and in cervical epithelium naturally infected by $C$. trachomatis (Swanson et al., 1975). Infection of ciliated epithelial cells and shedding of infected cells from the epithelial surface was evident. Despite this, however, ciliary activity was not seen to be affected, even though a quantitative method of assessment ${ }^{-}$was employed (McGee et al., 1976).

It is known that $C$. trachomatis may infect the tissues of the female genital tract without causing pathological or cytological changes, because chlamydiae have been isolated from women who show no signs of disease (Oriel et al., 1974), but there is also some evidence that chlamydiae may cause cervicitis (Rees et al., 1977) and salpingitis (Eilard et al., 1976; Mårdh et al., 1977). Our observations on experimental infection of oviduct cultures must raise the question of their relevance to such natural infections. There is clearly a dilemma. It is not possible to put forward the notion that the minimal changes produced in the organ cultures suggest that chlamydiae are likely to cause only minimal changes in vivo, because the organ culture system is unlikely to represent completely the in-vivo situation. Furthermore, without unquestionably knowing that C. trachomatis causes acute salpingitis it is difficult to use the model as a means of explaining the purported pathological changes. It is possible that the clinical disease occurs as a result of a combined infection with chlamydiae and other microorganisms or, alternatively, that tissue which has already been damaged by infection with another micro-organism provides a suitable environment for the growth of chlamydiae which take no active part in producing the disease. If, however, we assume that chlamydiae alone are involved in causing acute salpingitis, since recent evidence points further in that direction (Treharne et al., 1979), then it seems likely that the inflammatory changes-rather than being a direct effect of the organisms on the tissues, as may occur in gonococcal infections (Carney and Taylor-Robinson, 1973)-represent an immunological response of the host to chlamydial infection. This proposal would be compatible with the failure of chlamydiae to affect appreciably the tissues in organ culture where they are separated from the immunological systems of the host and would be in keeping with the known importance of immune factors in causing severe chlamydialstimulated disease in other anatomical areas such as the eye.

We thank $\mathrm{Mr}$ A. M. Fisher and $\mathrm{Mr} \mathrm{H}$. Gordon (Northwick Park Hospital) for providing Fallopian tubes and Dr R. N. Gourlay (Institute for Research on Animal Diseases, Compton) for helping us to 
obtain bovine oviducts. We also thank Mr C. Sowter and Mr J. Clark, for histopathology and photomicrography respectively, and Mr D. Shah for help with elecron microscopy.

\section{References}

Carney, F. E. jun. and Taylor-Robinson, D. (1973). Growth and effect of Neisseria gonorrhoeae in organ cultures. British Journal of Venereal Diseases, 49, 435-440.

Darougar, S., Cubitt, S., and Jones, B. R. (1974). Effect of highspeed centrifugation on the sensitivity of irradiated McCoy cell culture for the isolation of chlamydia. British Journal of Venereal Diseases, 50, 308-312.

Eilard, T., Brorsson, J-E., Hamark, B., and Forssman, L. (1976). Isolation of chlamydia in acute salpingitis. Scandinavian Journal of Infectious Diseases, Supplement 9, 82-84.

Johnson, A. P. Taylor-Robinson, D., McGee, Z. A., Melly, M. A., and Carney F. E. (1977). Preliminary studies on the mechanisms by which Neisseria gonorrhoeae damages host tissue. FEMS Microbiology Letters 1, 247-249.

Manire, G. C. (1977). Biological characteristics of chlamydiae. In Nongonococcal Urethritis and Related Infections, pp. 167-175. Edited by D. Hobson and K. K. Holmes. American Society for Microbiology: Washington D. C.

Mårdh P-A., Weström, L., von Mechlenburg, C. and Hammar, E. (1976). Studies on ciliated epithelia of the human genital tract. I. Swelling of the cilia of Fallopian tube epithelium in organ cultures infected with Mycoplasma hominis. British Journal of Venereal Diseases, 52, 52-57.
Mårdh P-A., Ripa, T., Svensson, L., and Weström, L. (1977). Chlamydia trachomatis infection in patients with acute salpingitis. New England Journal of Medicine, 296, 1377-1379.

McGee, Z. A., Johnson, A. P., and Taylor-Robinson, D. (1976). Human fallopian tubes in organ culture: preparation, maintenance, and quantitation of damage by pathogenic microorganisms. Infection and Immunity 13, 608-618.

Oriel, J. D., Powis, P. A., Reeve, P., Miller, A., and Nicol, C. S. (1974). Chlamydial infections of the cervix. British Journal of Venereal Diseases, 50, 11-16.

Prentice, M. J., Taylor-Robinson, D., and Csonka, G. W. (1976) Non-specific urethritis: a placebo-controlled trial of minocycline in conjunction with laboratory investigations. British Journal of Venereal Diseases, 52, 269-275.

Rees, E., Tait, I. A., Hobson, D., and Johnson, F. W. A. (1977). Chlamydia in relation to cervical infection and pelvic inflammatory disease. In Nongonococcal Urethritis and Related Infections, pp 67-76. Edited by D. Hobson and K. K. Holmes. American Society for Microbiology: Washington DC.

Stalheim, O. H. V., Proctor, S: J., and Gallagher, J. E. (1976). Growth and effects of ureaplasmas (T mycoplasmas) in bovine oviductal organ cultures. Infection and Immunity, 13, 915-925.

Swanson, J., Eschenbach, D. A., Alexander, E. R., and Holmes, K. K. (1975). Light and electron microscopic study of Chlamydia trachomatis infection of the uterine cervix. Journal of Infectious Diseases, 131, 678-687.

Taylor-Robinson, D. and Carney, F. E. jun. (1974). Growth and effect of mycoplasmas in Fallopian tube organ cultures. British Journal of Venereal Diseases, 50, 212-216.

Treharne, J. D., Ripa, K. T., Mårdh P-A., Svensson, L., Weström, L., and Darougar, S. (1979). Antibodies to Chlamydia trachomatis in acute salpingitis. British Journal of Venereal Diseases, 55, 26-29. 